\title{
Fabrication of High Yield Photoluminescent Quantized Graphene Nanodiscs for Supercapacitor Devices
}

\author{
Esraa Moustafa, Jehan El Nady, Abd El-Hady B. Kashyout,* Kamel Shoueir, and Maged El-Kemary
}

Cite This: ACS Omega 2021, 6, 23090-23099

Read Online

ABSTRACT: In this work, we produced high yield quantized nitrogen-doped graphene nanodiscs from waste tires via a one-step process under high pressure and temperature using a homemade stainless steel reactor without using any chemical additives. Reaction temperature played a vital role in the preparation process. By increasing the temperature to a level between 600 and $1100{ }^{\circ} \mathrm{C}$, the carbon atoms rearranged themselves to build a mixed graphene structure of nanodiscs and quantum dots. The obtained graphene exhibits excellent capacitance and long life cycle stability as an electrode in supercapacitor devices. The specific capacitance rose to $161.24 \mathrm{~F} / \mathrm{g}$ with a high power density of $733.3 \mathrm{~W} / \mathrm{kg}$, and the energy density reached $27.1 \mathrm{Wh} / \mathrm{kg}$. The finding of this work is not only to provide a solution to get rid of hazardous materials but also to give awareness of turning these hazardous materials into a cost-effective and economical nanomaterial; in another, this approach sheds light on the promising power uses of waste.

\section{INTRODUCTION}

Every year, millions of tires are discarded worldwide, and these amounts increased by increasing vehicle development. Some people get rid of waste tires by burning them up. This process is not only dangerous, but it also releases harmful gases and contributes significantly to air pollution. Many researchers reported different techniques to produce activated carbon from tires with the aid of varying catalysts. ${ }^{1,2}$ Types and amounts of the catalyst affect the surface area and pore size of the activated carbon and affect the carbon yield. Using potassium hydroxide as a catalyst, the intercalation of metallic potassium into the carbon network led to pore development, which accelerated the carbon losses. ${ }^{3}$ Generally, raw tires consist of around 52\% of rubber mixed between synthetic and natural rubber, oil, and organic and non-organic filler. ${ }^{4}$ Recently, Li et al. ${ }^{5}$ reported the fabrication of $3 \mathrm{D}$ graphene with an electrical conductivity of $18.26 \mathrm{~S} / \mathrm{cm}$ from tires using a potassium hydroxide-assisted pyrolysis technique at different temperatures under an argon atmosphere. Bonnia et al. ${ }^{6}$ fabricated graphene oxide using a modified Hummer's method followed by thermal exfoliation under nitrogen gas to produce graphene. Carbon-based dots (CBD) can be synthesized from tire wastes in more than one step using multiple chemicals. ${ }^{7}$

Nitrogen-doped graphene (NG) has a larger surface area, decreasing the resistance and increasing the electrical conductivity. Therefore, if we can find an economical way to use waste tires to produce a large scale of high-quality graphene, then there can be a market for it. Having more minor defects and being low cost, graphene will make a change in the industry as

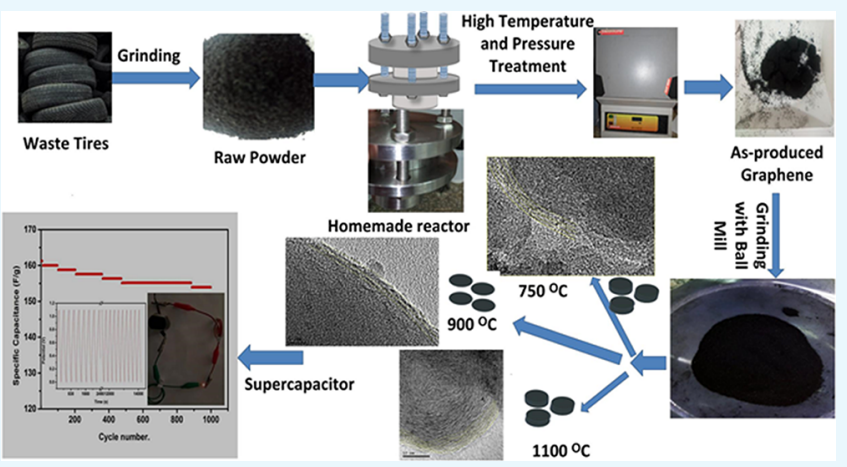

advanced electronics depend mainly on graphene for energy storage, solar cells, water treatment, etc. ${ }^{8}$ Different methods have been developed for graphene fabrication. Among them is chemical vapor deposition (CVD) that produces high-quality single and multilayer graphene with small amounts. ${ }^{9}$ The oxidation-reduction method, which involved oxidation of graphite to graphene oxide $(\mathrm{GO})^{10}$ and then reduced the GO to graphene, is considered a low-cost technique. Still, the end product has a high level of defects and contains a high oxygen content. $^{11}$

Energy storage devices took the world's attention as the variety of energy sources, so obtaining high efficiency energy storage devices with low cost and at the same time resolving environmental pollution is a great goal.

Supercapacitors are promising energy storage devices, and they are expected to replace lithium-ion batteries in the future. Supercapacitors have huge power densities comparable to batteries with high energy storage, unlike supercapacitors. ${ }^{12-14}$ Many researches focused on the fabrication of supercapacitors from biowaste materials like carbon waste to produce highperformance porous electrodes. Liu et al. ${ }^{15-17}$ produced porous

Received: May 8, 2021

Accepted: August 20, 2021

Published: September 1, 2021 
carbon from carbon waste. Wong et al. ${ }^{18}$ produced porous carbon from tea waste by using several steps from carbonization and activation using $\mathrm{KOH}$ and mixing them with a metal oxide to enhance the specific capacitance of the supercapacitor. In our early works, we demonstrated the fabrication of graphene oxide decorated with metal oxide nanoparticles. ${ }^{19,20}$ We fabricated low-cost, high quality, and large-scale nitrogen-doped graphene nanodiscs (N-GNDs) using a one-step process from waste tires in this work. The produced graphene could be applied as an active electrode material for supercapacitor devices.

\section{EXPERIMENTAL WORK}

2.1. Graphene Nanodisc Preparation. A weight of $14 \mathrm{~g}$ of the grinded waste tires was introduced in a stainless steel reactor (homemade), which has a strong cup head and is closed by four cap stainless steel screws, as shown in Scheme 1. Then, this

Scheme 1. Schematic Diagram for the Fabrication Process of N-GNDs from Waste Tires up to the Production of Supercapacitor Devices

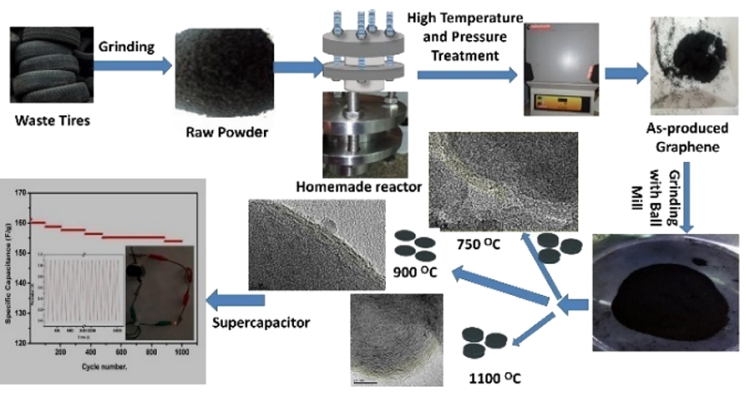

reactor was placed in a muffle furnace (Carbolite BWF 12/13 $1200{ }^{\circ} \mathrm{C}$ Lab Furnace). The treated temperature varied from 600 to $1100{ }^{\circ} \mathrm{C}$ with a rate of $10^{\circ} \mathrm{C} / \mathrm{min}$ during the temperature increase. The preparation conditions for the differently prepared samples are presented in Table 1. After that, the reactor was left

Table 1. Preparation Conditions for Graphene Nanodiscs and Yield

\begin{tabular}{cccc} 
sample ID & temperature $\left({ }^{\circ} \mathrm{C}\right)$ & time $($ hours $)$ & yield $(\%)$ \\
CW1 & 600 & 3 & 38 \\
CW2 & 750 & 3 & 37 \\
CW3 & 900 & 3 & 36.4 \\
CW4 & 1100 & 3 & 35.3 \\
\hline
\end{tabular}

to cool to room temperature in the muffle furnace, and the obtained black nanopowders were grinded by a ball mill (Planetary Micro Mill PULVERISETTE 7). The final powder yield was calculated as the produced nanopowder in grams divided by the introduced raw material $(14 \mathrm{~g})$ where there is no addition during the fabrication procedure. Yield efficiency slightly decreased as the curing temperature increased, indicating good tightness of the reactor to prevent any external air from burning the reactor's carbon content.

2.2. Electrochemical Measurements. The working electrode was prepared by mixing a slurry from the active graphene material (90 wt \%), carbon black (5 wt \%), and polyvinylidene fluoride (5 wt \%) using 1-methyl-2-pyrrolidinone as the solvent. A supporting nickel sheet with a thickness of $0.1 \mathrm{~mm}\left(1 \mathrm{~cm}^{2}\right)$ was covered by the slurry and then dried at 70 ${ }^{\circ} \mathrm{C}$ overnight. The mass density of the active material was about
1-2 mg/cm ${ }^{2} . \mathrm{Na}_{2} \mathrm{So}_{4}$ electrolyte solutions $(3 \mathrm{M})$ were used for electrochemical measurement, which was performed at room temperature using a potentiostat computer controller (Metrohm Autolab, model 870701), including galvanostatic chargedischarge (GCD), cyclic voltammetry (CV), and electrochemical impedance spectroscopy (EIS) within a potential range from 0 to $1 \mathrm{~V}$ and increasing the sweep rate from 5 to 200 $\mathrm{mV} / \mathrm{s}$. For CV measurements, the charge-discharge process was performed at different current densities ranging from 1 to 20 $\mathrm{A} / \mathrm{g}$. The specific capacitance was determined from GCD by ${ }^{21}$

$$
C=\frac{4 I \times \Delta t}{m \times \Delta V}
$$

and the energy and power density were calculated from ${ }^{22}$

$$
\begin{aligned}
& E=\frac{C \times \Delta V^{2}}{2 \times 3.6} \\
& P=\frac{E \times 3600}{\Delta t}
\end{aligned}
$$

where $I, \Delta t, m$, and $\Delta V$ represent the current density, discharge time, mass for two electrodes, and potential window, respectively.

\section{RESULTS AND DISCUSSION}

3.1. Raman Spectroscopy Analysis. Raman analysis is considered a non-destructive and rapid technique to investigate comprehensive properties of the graphitic materials like the disorder degree, which can be calculated from the ratio of $I_{\mathrm{G}} / I_{\mathrm{D}}$. The $\mathrm{D}$ band corresponds to the first-order scattering of $\mathrm{sp}^{2}$ hybridized disordered carbon materials. The $G$ band is due to the Raman active vibrational mode E2g observed for the crystallinity of the graphitized carbon network. ${ }^{23}$ There are three central regions for the Raman spectra. The measured data are CW, CW1, CW2, CW3, and CW4. The first region lies between 200 and $800 \mathrm{~cm}^{-1}$ and is shown in Figure S1a,b. The CW sample shows a high hump at the start of the measurement. There are three peaks at $281.5,321.5$, and $640 \mathrm{~cm}^{-1}$ that correspond to the $\mathrm{Ag}, \mathrm{B} 1 \mathrm{~g}$, and $\mathrm{B} 2 \mathrm{~g}$ modes of the $\mathrm{CuO}$ structure, respectively. ${ }^{24}$ With increasing the heat treatment to higher temperatures, the position and intensities of these peaks changed as a blue shift of the $\mathrm{Ag}$ and $\mathrm{B} 1 \mathrm{~g}$ has been detected. This could happen due to the $\mathrm{ZnO}$ 's existence in raw materials ${ }^{25}$ converted to $\mathrm{ZnS}$ at higher temperatures, as shown in Figure S1b. The second region lies between 1300 and $2000 \mathrm{~cm}^{-1}$, as shown in Figure 1, and is characterized by D and G bands at 1326-1357 and 1526-1592 $\mathrm{cm}^{-1}$, respectively. Table $S 1$ summarizes the numerical values for $\mathrm{D}, \mathrm{G}$, and $2 \mathrm{D}$ bands and their related intensities as well as the ratio of $I_{\mathrm{D}} / I_{\mathrm{G}}$ and $I_{2 \mathrm{D}} / I_{\mathrm{G}}$. The least values of $I_{\mathrm{D}} / I_{\mathrm{G}}$ are recorded for CW3 and CW1 with values of 0.948 and 0.974 , respectively, and the highest one for CW4 and CW2 with values of 1.54 and 1.27 , respectively. The intensity of the $G$ peak increases dramatically by increasing the temperature to reach the maximum for the $\mathrm{CW} 4$ sample treated at $1100{ }^{\circ} \mathrm{C}$. This indicates that, by increasing the heat treatment, the crystallinity increases. ${ }^{26}$ The crystallite size $\left(L_{\mathrm{a}}\right)$ in nanometers is calculated from the general equation: ${ }^{27}$

$$
L_{a}(\mathrm{~nm})=\left(2.4 \times 10^{-10}\right) \lambda^{4}\left(\frac{I_{\mathrm{D}}}{I_{\mathrm{G}}}\right)^{-1}
$$




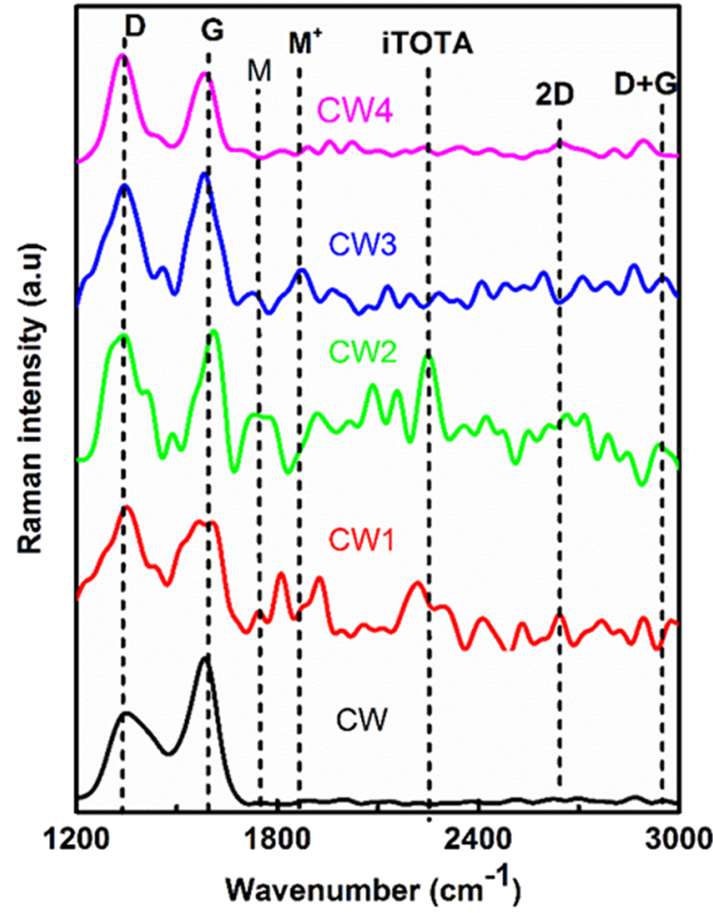

Figure 1. Raman spectra of CW, CW1, CW2, CW3, and CW4 between 1200 and $3000 \mathrm{~cm}^{-1}$.

The crystallite sizes are calculated and summarized in Table S1. The maximum crystallite size of 17.8 is recorded for the sample treated at $900{ }^{\circ} \mathrm{C}$ (CW3), while the minimum value of $10.9 \mathrm{~nm}$ is recorded for $\mathrm{CW} 2$ treated at $750{ }^{\circ} \mathrm{C}$. This sample (CW2) recorded a maximum value of $I_{2 \mathrm{D}} / I_{\mathrm{G}}$ of 0.653 , indicating more defects with a lower number of GND layers. In contrast, sample CW4 recorded the minimum $I_{2 \mathrm{D}} / I_{\mathrm{G}}$ values of 0.26 , indicating lower defects with a high number of layers, as indicated in high-resolution transmission electron microscopy (HRTEM) in Figure 2. There is more than one band detected between $\mathrm{G}$ and $2 \mathrm{D}$ bands. The first one that appeared at around $1733 \mathrm{~cm}^{-1}$, which is related to $\mathrm{M}$, and another peak that occurs at about $1860 \mathrm{~cm}^{-1}$ are associated with a similar fashion of $\mathrm{M}$ mode ( $M$ mode has two peaks, one around $1733 \mathrm{~cm}^{-1}$ and then another around $\left.1860 \mathrm{~cm}^{-1}\right),{ }^{28}$ which refers to the strong stacking between graphene layers. ${ }^{29,30}$ Another peak related to iTOTA appeared at around $2245 \mathrm{~cm}^{-1}$, which ensures the high stacking between graphene layers and is observed to decrease with increasing graphene layers. These peaks appeared obviously in CW1 and CW2 and almost vanished at CW3 and CW4. D + G mode appeared at around $2947 \mathrm{~cm}^{-1}$, which is related to size: as the size increases, the intensity of this band increases. $^{26}$

3.2. Transmission Electron Microscopy Analysis. TEM images for CW2, CW3, and CW4 are shown in Figure 2, which are heat-treated at 750,900 , and $1100{ }^{\circ} \mathrm{C}$, respectively. The two samples at lower-treated temperatures (CW2 and CW3) exhibit round discs in the range between 30 and $50 \mathrm{~nm}$, while at a higher temperature, the diameters of the round discs increase to about 50-70 nm. At higher resolution for sample CW2, as shown in Figure 2c, nanoparticles of sizes $5-7 \mathrm{~nm}$ are circled in yellow, referred to as zinc oxide (converted to $\mathrm{ZnS}$ at higher temperatures) and $\mathrm{CuO}$ in the raw materials, as will be discussed in XRD results. These nanoparticles are decreased in the sample treated at $900{ }^{\circ} \mathrm{C}(\mathrm{CW} 3)$ (Figure 2f) and sample treated at 1100

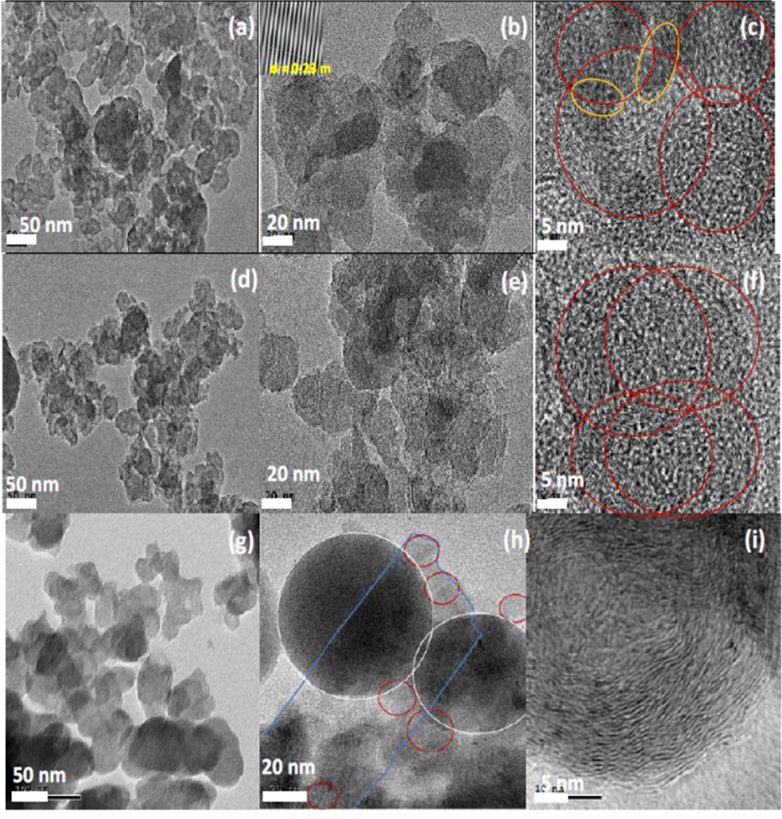

Figure 2. TEM images of sample CW2 $(a-c)$ and HRTEM, $(d, e)$ for sample CW3 and (f) HRTEM, and TEM of sample CW4 (g, h) and HRTEM (i). The inset of panel (b) shows the fringes and $d$-spacing of graphene.

${ }^{\circ} \mathrm{C}(\mathrm{CW} 4)$, as shown in Figure 2i. Also, the number of layers shown in Scheme 1 is about 5 for CW2, decreased to 3 in CW3, and increased to about 25 in CW4. This thickening in the layers either at lower temperature $\left(750{ }^{\circ} \mathrm{C}\right)$ or at $1100{ }^{\circ} \mathrm{C}$ yielded stable graphene nanodiscs with higher $\mathrm{PL}$, while thinner graphene nanodiscs yielded lower PL, as clearly detected in Figure 5. The inset of Figure $2 b$ shows the fringes of GNDs with a $d$-spacing value of $0.23 \mathrm{~nm}$. ${ }^{32}$

3.3. Crystal Structure Analysis. The crystal structure changing with temperature is recorded by X-ray diffraction patterns (XRD), as shown in Figure 3 for all samples shown in

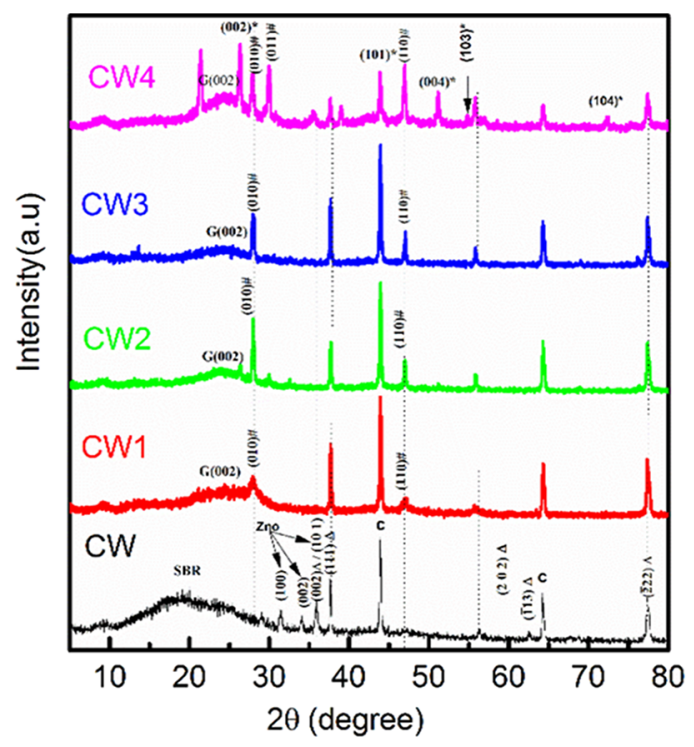

Figure 3. $\mathrm{XRD}$ patterns for raw waste tire $(\mathrm{CW})$ and all treated samples at $600{ }^{\circ} \mathrm{C}(\mathrm{CW} 1), 750{ }^{\circ} \mathrm{C}(\mathrm{CW} 2), 900{ }^{\circ} \mathrm{C}(\mathrm{CW} 3)$, and $1100{ }^{\circ} \mathrm{C}$ (CW4). (Asterisks $(*)$ represent the graphitic structure, "G" represents graphene, “\#” represents $\mathrm{ZnS}$, and $\Delta$ represents $\mathrm{CuO}$ ). 
Table 1. The waste tire structure (raw material) consists of natural rubber, SBR (styrene butadiene rubber), and carbon black used as a filler to add some amounts of zinc oxide, nitrogen source, and small values for silica. The broad peak in the raw material $(\mathrm{CW})$ represents $\mathrm{SBR} .^{33}$ The peaks at around $2 \theta=44$ and $64^{\circ}$ represent the carbon structure (JCPDS card no. 01-0751621) as when adding carbon black to rubber as a filler can turn carbon from an amorphous structure to a crystalline structure. $^{33,34}$ In the raw material $(\mathrm{CW})$, the peaks around $2 \theta$ of $36.6,37.6,56,64$, and $77^{\circ}$ correspond to the planes of $(002)$, (111), (202), (113), and (222), respectively, which represent the $\mathrm{CuO}$ structure (JCPDS card no. 45-0937). Some of these planes continued after heat treating the samples, such as (111) with higher intensity, and others decreased or vanished. Planes of (100), (002), and (101) are crystallographic representations at $2 \theta=31.8,34.5$, and $36.3^{\circ}$, respectively, which correspond to the Wurtzite phase of the $\mathrm{ZnO}$ structure (JCDPS card no. 361451). By increasing the curing temperature in the closed system and in the presence of sulfur, which rubber contains, zinc oxide turned to zinc sulfide. The $2 \theta$ values around 28,47 , and $56^{\circ}$ correspond to planes of (010), (110), and (020), respectively, which represent the Wutzrite zinc sulfide (JCPDS card no. 361450). The broaden peak at around $2 \theta=20^{\circ}$ representing the SBR started to shift by increasing the temperature around $2 \theta=$ $25^{\circ} .^{35}$ This means that the carbon atoms began to rearrange themselves to produce graphene layers. ${ }^{36}$ For sample CW4, it shows the appearance of the graphite structure (peaks around $2 \theta$ $=26.2,43.8,51,55$, and $\left.72.5^{\circ}\right)$, which represent planes of $(002)$, (101), (004), (103), and (104), respectively (graphite $2 \mathrm{H}$, JCPDS card no. 01-075-1621). From the XRD patterns in Figure 3 and TEM images in Figure 2, they investigate that the waste tires under pressure and temperature started to lose hydrogen atoms. The carbon began to form a graphene quantum dot structure at $600{ }^{\circ} \mathrm{C}$. At $900{ }^{\circ} \mathrm{C}$, all of the carbon atoms are transferred to GQD, the multiple structures started to create nanodiscs, and these discs started to recombine to confirm multilayer discs, as shown in Scheme 2. At $1100^{\circ} \mathrm{C}$, the number

Scheme 2. Schematic Representation of the Proposed Growth Process

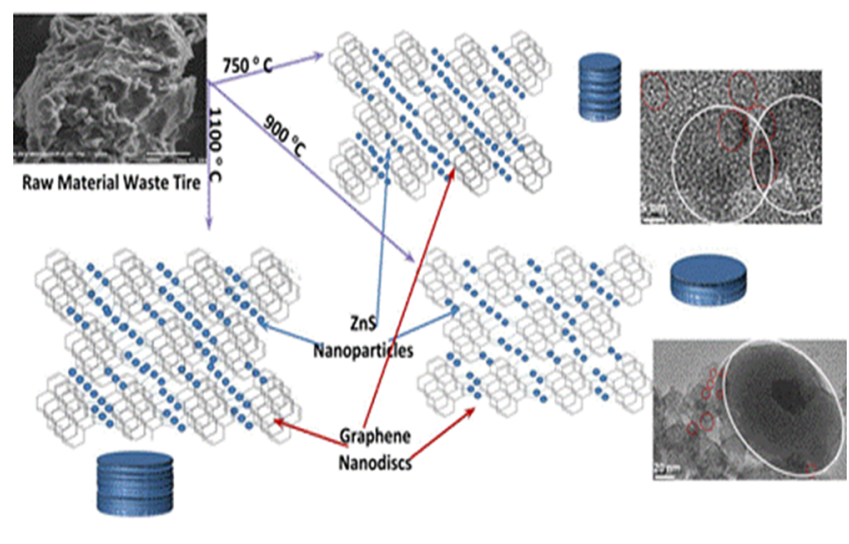

of layers increased, which could behave as an artificial graphite structure consisting of a multidisc structure. The peak around $21.3^{\circ}$ may be related to a highly crystalline graphene structure. XRD of CW4 revealed that it is composed of the graphene/ GNDs/graphite structure. ${ }^{37}$

Figure S2 shows different TEM and HRTEM of samples CW1, CW3, and CW4 and selected area electron diffraction (SAED) measurement for sample CW3 that reveals the polycrystalline nature combined with amorphous rings, as shown in the XRD results of the same samples.

3.4. X-ray Photoelectron Spectroscopy Analysis. The elemental chemical states and the chemical composition of GQDs can be detected by X-ray photoelectron spectroscopy (XPS). From the survey spectra of CW3 (Figure 4E), the prominent graphitic $\mathrm{C} 1 \mathrm{~s}$ appears at $284.8 \mathrm{eV}$, the $\mathrm{O} 1 \mathrm{~s}$ peak appears at $532.9 \mathrm{eV}$, and also, there are small amounts of N1s, $\mathrm{Si} 2 \mathrm{p}$, and $\mathrm{Zn} 2 \mathrm{p}$, which occur at 400,104 , and $1022.43 \mathrm{eV}$, respectively. The atomic ratio of $\mathrm{O} / \mathrm{C}$ is $15 \%$. The deconvolution of C1s (Figure 4A) shows that there are three distinctive peaks that may contribute to the carbon 1 s core level region, and the major peak appears at $284.17 \mathrm{eV}$ corresponding to $\mathrm{C}-\mathrm{C}\left(\mathrm{sp}^{2}\right.$-hybridized, graphitic structure $) .^{38-43}$ This accounts for $78.21 \%$ of all carbon intensities. The second peak at $286.1 \mathrm{eV}$ reflects $\mathrm{C}-\mathrm{N}$ and $\mathrm{C}=\mathrm{N}$ bonds and represents $9.48 \%$ of all carbon intensities. ${ }^{41-43}$ The third peak at $288 \mathrm{eV}$ represents the carboxylate group $(\mathrm{O}-\mathrm{C}=\mathrm{O}),{ }^{41,44,45}$ representing $\sim 12.31 \%$ of all carbon intensities. In O1s (Figure 4B), three prominent peaks appear at 532.67, 531.15, and $533.17 \mathrm{eV}$, attributed to $\mathrm{Si}-\mathrm{O}-\mathrm{Si}, \mathrm{C}-\mathrm{O}$, and $\mathrm{C}=\mathrm{O}$, respectively. ${ }^{43-47}$ In N1s (Figure 4C), the detected peak at $399.58 \mathrm{eV}$ represents the pyrrolic N41. Zn2p (Figure 4D) has three peaks at binding energies of 1021.99 and $1023.18 \mathrm{eV}$ assigned to $\mathrm{Zn} 2 \mathrm{p}_{3 / 2}$ and $1045.14 \mathrm{eV}$ for $\mathrm{Zn} 2 \mathrm{p}_{1 / 2}$, which represents the zinc sulfide structure. $^{48}$

3.5. Fourier Transform Infrared Spectroscopy Analysis. Investigating chemical bonds and related chemical groups using Fourier transform infrared (FT-IR) spectroscopy helped us detect the produced nanopowders' expected chemical structure. In Figure S3a, which represents FT-IR of the raw material, the peaks of styrene butadiene rubber (SBR) and natural rubber $(\mathrm{NR})^{49}$ appear at 684 and $2921 \mathrm{~cm}^{-1}$. These two peaks disappeared in the treated samples, as shown in Figure $\mathrm{S} 3 \mathrm{~b}$, which means a complete decomposition of rubber to the carbon structure. Other peaks appear in Figure S3a at 1389 and $3460 \mathrm{~cm}^{-1}$ that are related to the hydroxyl group and disappear in the prepared samples, as shown in Figure S3b, which indicates that the dehydration/polymerization process occurred for the prepared samples. ${ }^{50}$ As shown in Figure S3b, all samples exhibit a characteristic peak at around $1587 \mathrm{~cm}^{-1}$ corresponding to $\mathrm{C}=$ $\mathrm{C}\left(\text { aromatic, } \mathrm{sp}^{2}\right)^{45}$ and another peak related to $\mathrm{C}-\mathrm{O}-\mathrm{C}^{51,52}$ appeared at about $1100 \mathrm{~cm}^{-1}$. It is apparent that, by increasing the temperature, the intensity of the $\mathrm{C}=\mathrm{C}$ peak increased and $\mathrm{C}-\mathrm{O}-\mathrm{C}$ decreased, and no peaks for the $\mathrm{OH}$ group are detected, although it appears in the as-received sample (CW). The peak around $593 \mathrm{~cm}^{-1}$ represents $\mathrm{Cu}-\mathrm{O},{ }^{53}$ and it is shifted to a lower wavenumber for fabricated powders, which appears around $470 \mathrm{~cm}^{-1}$.

3.6. Optical Absorption and Photoluminescence Study. The absorbance and photoluminescence (PL) measurements were carried out to understand the influence of temperature on the optical properties of graphene nanodiscs. Figure 5A shows the optical absorption spectra (left) and photoluminescence spectra (right) of graphene nanodiscs CW1, CW2, CW3, and CW4 upon excitation at $290 \mathrm{~nm}$. The samples displayed a strong emission peak at about $345 \mathrm{~nm}$. The insets display the photographs of the excited samples that exhibit blue PL emissions. The highest PL emission intensity was shown for sample CW2 (treated at $750{ }^{\circ} \mathrm{C}$ ) followed by CW1 (treated at $600^{\circ} \mathrm{C}$ ). Samples CW3 and CW4 showed the lowest emission intensity. The decrease in intensity for CW3 and CW4 may be related to increasing the size of GNDs as a result of the fusion of 

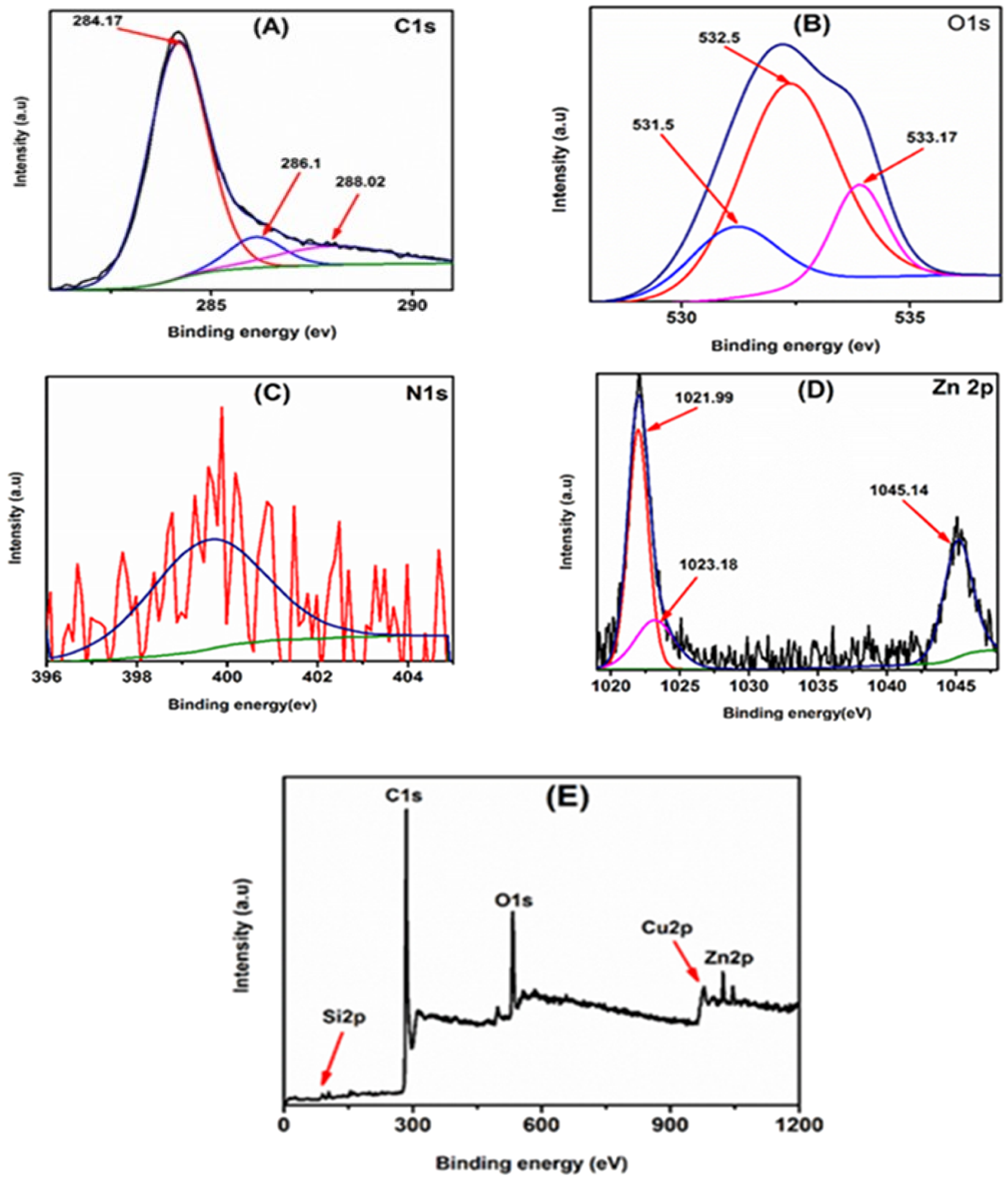

Figure 4. XPS analysis for the CW3 sample: (A) C1s, (B) O1s, (C) N1s, (D) Zn2p, and (E) general survey.

small GQDs that caused quenching of the blue light emission. The calculated fluorescence quantum yield according to eq 5 increases in the same order as $\mathrm{Qf}(\mathrm{CW} 2)>\mathrm{Qf}(\mathrm{CW} 1)>$ $\mathrm{Qf}(\mathrm{CW} 3)>\mathrm{Qf}(\mathrm{CW} 4)$. The decrease in fluorescence intensity and fluorescence quantum yield with increasing the temperature reflects the role of thermal energy in establishing electron-hole (exciton) radiative recombination leading to decreasing the fluorescence intensity.
The fluorescence quantum yield (Qf) can be calculated by using the comparative method. ${ }^{54}$ The quantum yield for GNDs also can be obtained from the following equation:

$$
\phi_{x}=\phi_{\text {std }}\left(\frac{F_{x}}{F_{\text {std }}}\right)\left(\frac{A_{\text {std }}}{A_{X}}\right)\left(\frac{n_{x}}{n_{\text {std }}}\right)^{2}
$$

where $\phi, F, A$, and $n$ are the quantum yield, integrated fluorescence intensity, integrated absorbance intensity, and refractive index, respectively. "std" represents the standard 

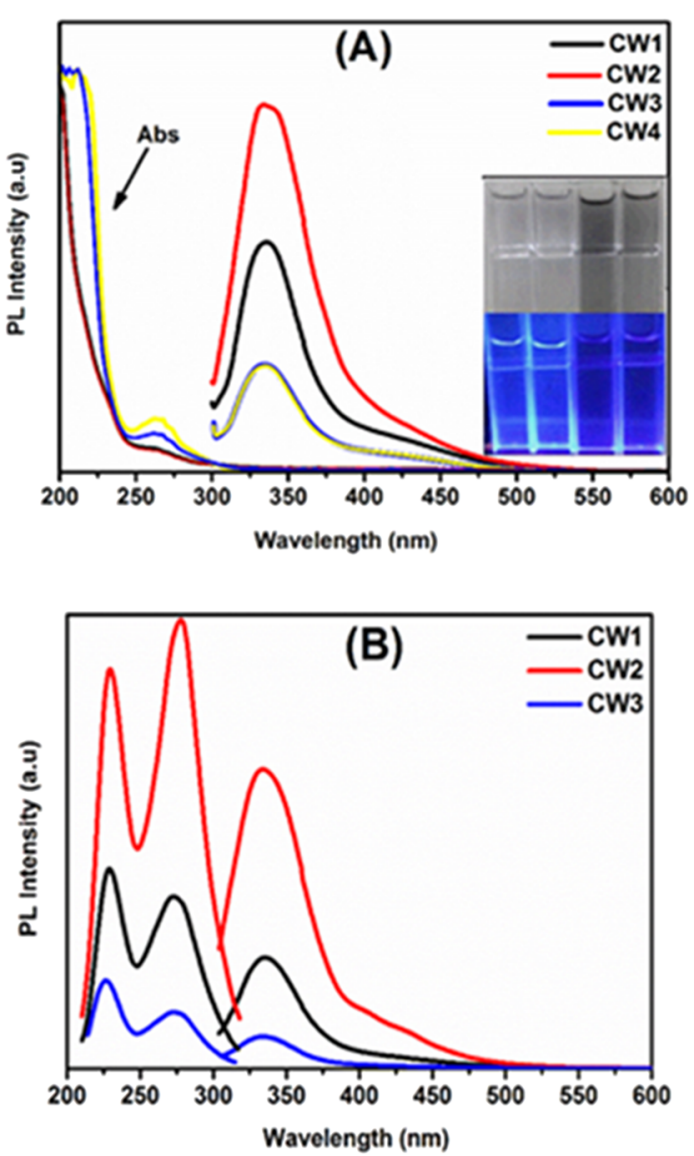

Figure 5. (A) PL emission spectra upon excitation of $290 \mathrm{~nm}$. Inset: photograph of the graphene ethanolic solution taken under $365 \mathrm{~nm} \mathrm{UV}$ light for samples started by CW1, CW2, CW3, and CW4 from left to right. (B) PL of the same graphene ethanolic solutions after storing at room temperature for 48 days.

fluorophore-known quantum yield. In this work, quinine sulfate was used with low concentration to minimize the reabsorption effect. The quantum yield of quinine sulfate dissolved in $0.1 \mathrm{M}$ $\mathrm{H}_{2} \mathrm{SO}_{4}\left(n_{\text {std }}=1.33\right)$ is $0.54 .^{55}$ The synthesized GNDs were calculated from the previous equation and are summarized in Table 2.

Table 2. Calculated Quantum Yield of the Prepared Samples

\begin{tabular}{cc} 
sample & FLQY (\%) \\
CW1 & 2.50 \\
CW2 & 4.41 \\
CW3 & 1.16 \\
CW4 & 0.26 \\
\hline
\end{tabular}

However, GNDs showed more extended stability than graphene quantum dots, as reported previously, ${ }^{32}$ where GNDs can be stable for a year in air at room temperature and still have a transparent appearance and strong PL. These samples are measured after depositing for several months of their fabrication, which means promising nanomaterials that explore a quantified nanographene behavior. Figure 5B shows the PL measurements for the same ethanolic solution samples measured in Figure 5A after storing them at room temperature for 48 days. Here, we notice the disappearance of CW4, which means that sample CW4 has the lowest stability in ethanolic solution.
3.7. Thermal Gravimetric Analysis. Figure S4 shows the thermal gravimetric analysis of raw materials CW, CW1, and CW3. The CW raw material shows more than one mass loss stage (Figure S4a). However, there is no obvious change from 19 to $200{ }^{\circ} \mathrm{C}$ (mass losses of $0.62 \%$ ), indicating less moisture in the waste tire sample. The mass losses $(48.62 \%)$ at a temperature between 200 and $500{ }^{\circ} \mathrm{C}$ may be due to the thermal degradation of additives to tires like oil and plasticizers (from 200 to 329.95 ${ }^{\circ} \mathrm{C}$ ). The decomposition of natural rubber and synthetic rubber occurs (from 329.95 to $600{ }^{\circ} \mathrm{C}$ ). The stage from 600 to $888^{\circ} \mathrm{C}$ (mass losses from 500 to $888{ }^{\circ} \mathrm{C}$ equal 42.29\%) is released to carbon black and used as a filler in tires. The last stage, from 888 to $1000{ }^{\circ} \mathrm{C}$, represents an inorganic filler (8.43\%). ${ }^{49}$ Sample CW3 shows more thermal stability than CW1, as shown in Figure $\mathrm{S} 4 \mathrm{~b}$ as it lost only $6.8 \%$ from ambient temperature to $501.34{ }^{\circ} \mathrm{C}$, while CW1 lost $9.45 \%$ from ambient temperature to $444.69{ }^{\circ} \mathrm{C}$. The two samples sharply decomposed, starting at $444.69^{\circ} \mathrm{C}$ for $\mathrm{CW} 1$ and $501.34{ }^{\circ} \mathrm{C}$ for CW3. This sharp decrease may indicate that small sizes of graphene nanodiscs are fused to form large ones, so at higher temperatures $\left(900^{\circ} \mathrm{C}\right)$, the thermal stability increased. ${ }^{56,57}$ CW3 loses $81.59 \%$ between 29.94 and $625.17^{\circ} \mathrm{C}$, while CW3 loses $82.81 \%$ between 31.62 and 598.73 ${ }^{\circ} \mathrm{C}$. Also, CW1 reached its stable state at $598.73{ }^{\circ} \mathrm{C}$ with a remaining weight of $18.26 \%$, while CW3 reached stability at $625.17{ }^{\circ} \mathrm{C}$ with a remaining weight of $19.43 \%$.

3.8. Specific Surface Area Analysis. The specific surface area can be estimated by the $\mathrm{N} 2$ adsorption-desorption curve, as shown in Figure S5. The specific surface area of CW3 reaches $105.6 \mathrm{~m}^{2} / \mathrm{g}$, and CW is $49.59 \mathrm{~m}^{2} / \mathrm{g}$. The high pore distribution of CW3 has a diameter of nearly $4.9 \mathrm{~nm}$ (with a pore volume of $\left.0.09 \mathrm{~cm}^{3} / \mathrm{g}\right){ }^{50}$ Scheme 2 discusses the proposed growth mechanism by demonstrating how temperature and pressure converted the raw material waste tires to nanocarbon structures. Increasing the temperature causes a dehydration process accompanied by the decomposition of the synthetic and natural rubber with the existence of carbon black and $\mathrm{ZnO}$. Carbon atoms started to rearrange themselves to produce GNDs with 30-50 nm dimensions, and $\mathrm{ZnO}$ turned to $\mathrm{ZnS}$. At $750{ }^{\circ} \mathrm{C}$, the number of layers ranged between three and five layers, and by increasing the temperature to $900{ }^{\circ} \mathrm{C}$, the pressure inside the reactor caused the layers to separate and form GNDs up to three layers. At higher temperatures $\left(1100{ }^{\circ} \mathrm{C}\right), \mathrm{ZnS}$ started to link GNDs to form larger GNDs $(50-70 \mathrm{~nm})$, which caused quenching of the PL emission, as shown in the inset of Figure 5. This process caused the accumulation of these larger GNDs to form thick layers of graphitized carbon, as evidenced by TEM images, XRD, and PL data.

3.9. Electrochemical Measurements. Cyclic voltammetry (CV) was used to identify the electrochemical behavior of the GND method using a two-electrode technique (2E) cell with 3 $\mathrm{M} \mathrm{Na}_{2} \mathrm{So}_{4}$ as an aqueous electrolyte. Figure $6 \mathrm{~A}$ shows the quasirectangular shape for all samples at a scan rate of $100 \mathrm{mV} / \mathrm{s}$ with a potential window from 0 to $1 \mathrm{~V}$. The observed $\mathrm{CV}$ profile is nearly symmetrical in the potential window from 0 to $1 \mathrm{~V}$ without any distinct peaks, indicating a typical characteristic of energy double-layer capacitance (EDLC), ${ }^{58}$ ensuring that the copper oxide and zinc sulfide do not appear at the GND surface. It is observed that sample CW3 has a much larger enclosed area and the best rectangular shape with the highest current density compared to other samples with a distorted rectangular shape. This indicates that CW3 has the lowest internal resistance with acceptable electrical conductivity and the largest specific capacitance. ${ }^{22}$ Figure $6 \mathrm{~B}$ shows the $\mathrm{CV}$ of $\mathrm{CW} 3$ at different 

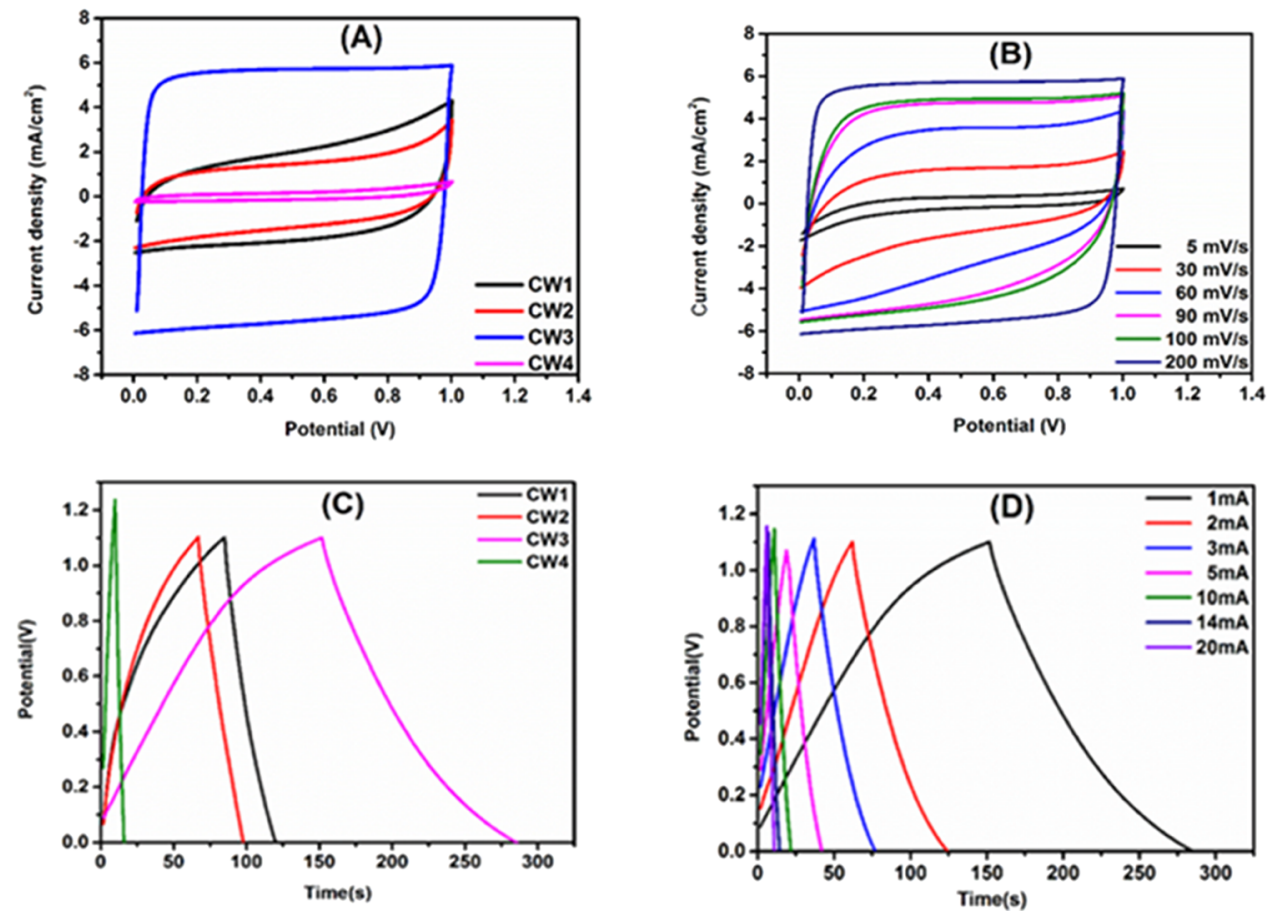

Figure 6. Electrochemical measurements of GND electrodes: (A) CV curves of all samples at $100 \mathrm{mV} / \mathrm{s}$ in $3 \mathrm{M} \mathrm{Na}_{2} \mathrm{So}_{4}$, (B) CV curves of CW4 at different scan rates (notice that, by increasing the scan rate, the current densities are linearly grown), (C) galvanostatic charge and discharge for all samples at $1 \mathrm{~A} / \mathrm{g}$ in $3 \mathrm{M} \mathrm{Na}_{2} \mathrm{So}_{4}$, and (D) GCD of CW4 at different current densities (from 1 to $20 \mathrm{~A} / \mathrm{g}$ ).

scan rates from 5 to $200 \mathrm{mV} / \mathrm{s}$ without any distortion in the quasi-rectangular shape. This refers to the noticeable perfect charge distribution in the capacitive behavior, low contact resistance, and excellent stability. ${ }^{59}$ The GND supercapacitor electrodes are also tested by the galvanostatic charge-discharge (GCD) process. As shown in Figure 6C, the GCD demonstrates a symmetric shape for all samples and no apparent IR drop at 1 $\mathrm{A} / \mathrm{g}$ in $3 \mathrm{M} \mathrm{Na}_{2} \mathrm{So}_{4}$ that indicates excellent carrier transport through the material. The shape is nearly like an ideal EDLC supercapacitor. ${ }^{60}$ Furthermore, CW3 has the highest discharge time compared to other samples, which means that it has the largest specific capacitance. The charge and discharge galvanostatic behavior at different current densities from 1 to $20 \mathrm{~A} / \mathrm{g}$ are shown in Figure $6 \mathrm{D}$. This influence revealed the absence of any distortion, which means that the GND electrode has excellent stability at high current densities, as shown in Figure 6C. In addition, the specific capacitance of the samples can be calculated from GCD using eq 1 as particular capacitances are equal to $41.2,35.1,161.2$, and $7.27 \mathrm{~F} / \mathrm{g}$ for CW1, CW2, CW3, and CW4, respectively. The CW3 sample exhibited a higher specific capacitance than the other samples likely because it possesses the lowest number of GND layers compared to other prepared samples, which means that it has a higher electrical conductivity because the bandgap will open up and affect its electron mobility. ${ }^{59}$ The energy and power density can be calculated using eqs 2 and 3. The calculated energy density and power density for all samples are illustrated in Table S2. CW3 has an energy density of $27.1 \mathrm{Wh} / \mathrm{kg}$ and a power density of $733.3 \mathrm{~W} / \mathrm{kg}$ at a current density of $1 \mathrm{~A} / \mathrm{g}$, which is the highest value between all other samples as indicated above.

We performed EIS analysis to test the properties of electrolyte diffusion and capacitive resistance. ${ }^{58}$ Figure S6a shows Nyquist plots for all sample electrodes. The absence of a semicircle in all samples at high frequency and a straight line at low frequency indicates the excellent ion diffusion through the active material, best adhesion ${ }^{61,62}$ between the active material and substrate, and superior energy double-layer capacitance behavior of the supercapacitor. The $x$ axis (Rs) intercept is small (from 0.198 to $0.29 \mathrm{ohm}$ ), which refers to low internal resistance, ionic electrolyte resistance, and small resistance between the active material and substrate. In Table S3, it is noticed that the Rs of CW3 is larger than the other samples, which may be due to the defect formation on the surface of CW3 during preparation. ${ }^{63}$ The equivalent circuit of CW3 is represented in Figure S6B, where "Rs" is the series resistance, "CPE" is a constant phase element that means EDLC, "W" represents the Warburg element related to ion diffusion, and " $\mathrm{L}$ " is an inductor. The equivalent circuit for GNDs for the liquid electrolyte interface may be characterized as a constant phase element (CPE) rather than an ideal capacitor. ${ }^{64-67} \mathrm{Y} 0$ and $\mathrm{N}$ are the fitted parameters for CPE representing the numerical values of admittance and phase angle of impedance, respectively. The ideal capacitor has $N=1$, as shown in Table $\mathrm{S} 3$, where all samples nearly behave as a perfect capacitor. The Bode plot in Figure S6c describes the performance of the impedance phase angle with respect to frequency. It is evident that the sample performance at low frequency represents supercapacitor behavior; CW3 has a phase angle close to $80^{\circ}$ but in high frequency. The relaxation time is an inverse of frequency at an angle of $45^{\circ} .{ }^{58}$ It has an alternating value between 9.2 and $126 \mathrm{~ms}$ as the nanosized and edge defect of GNDs led to a decreasing relaxation time, maintaining the rapid response of adsorption and enriching the ion transport rate at the interface between the electrode and electrolyte. ${ }^{68}$ Figure S6d shows the stability of the CW3 supercapacitor, and it exhibits high stability as the specific capacitance retention after 1000 cycles reaches $95.4 \%$, meaning stable GND materials as evidenced from the PL measurement. 


\section{CONCLUSIONS}

The present work demonstrated the utilization of high yield conversion $(\sim 40 \%)$ of waste wires to valuable graphene nanodiscs (GNDs) with different architectures depending on the treated temperature at high pressure in a closed stainless steel reactor. High-quality photoluminescence quantized $\mathrm{N}$ GNDs have been synthesized and detected with a stable and high quantum yield. GNDs mixed with GQDs depending on the temperature treatment significantly affect linking $\mathrm{ZnS}$ nanoparticles with GNDs to assemble a larger diameter and multilayers of the structure. These GNDs showed highperformance supercapacitors with high specific capacitance and high stability that reached $95.4 \%$ after 1000 cycles.

\section{ASSOCIATED CONTENT}

\section{(s) Supporting Information}

The Supporting Information is available free of charge at https://pubs.acs.org/doi/10.1021/acsomega.1c02277.

Supporting information containing information about the raw material, devices used in characterization, and some analyses results (TGA, FT-IR, Raman, and electrochemical) (PDF)

\section{AUTHOR INFORMATION}

\section{Corresponding Author}

Abd El-Hady B. Kashyout - Electronic Materials Department, Advanced Technology and New Materials Research Institute, City of Scientific Research and Technological Applications (SRTA-City), Alexandria 21934, Egypt; ○ orcid.org/00000002-9185-740X; Email: hady8@yahoo.com, akashyout@ srtacity.sci.eg

\section{Authors}

Esraa Moustafa - Institute of Nanoscience \& Nanotechnology, Kafrelsheikh University, Kafrelsheikh 33516, Egypt

Jehan El Nady - Electronic Materials Department, Advanced Technology and New Materials Research Institute, City of Scientific Research and Technological Applications (SRTACity), Alexandria 21934, Egypt; 이이.org/0000-00022745-3339

Kamel Shoueir - Institute of Nanoscience \& Nanotechnology, Kafrelsheikh University, Kafrelsheikh 33516, Egypt; (1) orcid.org/0000-0001-7994-559X

Maged El-Kemary - Institute of Nanoscience \& Nanotechnology, Kafrelsheikh University, Kafrelsheikh 33516, Egypt

Complete contact information is available at:

https://pubs.acs.org/10.1021/acsomega.1c02277

\section{Notes}

The authors declare no competing financial interest.

\section{ACKNOWLEDGMENTS}

E.M. would like to thank Dr. Wael Wazeer from the City of Scientific Research and Technological Applications (SRTACity), New Borg El-Arab City, Alexandria, Egypt, for his technical and valuable assistance.

\section{REFERENCES}

(1) Mashile, P. P.; Dimpe, M. K.; Omngongo, P. N. Application of waste tyre-based powdered activated carbon for the adsorptive removal of cylindrospermopsin toxins from environmental matrices: Optimiza- tion using response surface methodology and desirability function. $J$. Environ. Sci. Health, Part A: Toxic/Hazard. Subst. Environ. Eng. 2019, 54, 679-685.

(2) Zhi, M.; Yang, F.; Meng, F.; Li, M.; Manivannan, A.; Wu, N. Effects of Pore Structure on Performance of An Activated-Carbon Supercapacitor Electrode Recycled from Scrap Waste Tires. ACS Sustainable Chem. Eng. 2014, 2, 1592-1598.

(3) Hui, T. S.; Zaini, M. A. A. Potassium hydroxide activation of activated carbon: a commentary. Carbon Letters. 2015, 16, 275-280.

(4) Lu, Q.; Toled, R. A.; Xie, F.; Li, J.; Shim, H. Reutilization of waste scrap tyre as the immobilization matrix for the enhanced bioremoval of a monoaromatic hydrocarbons, methyl tert-butyl ether, and chlorinated ethenes mixture from water. Sci. Total Environ. 2017, 583, 88-96.

(5) Wang, C.; Li, D.; Zhai, T.; Wang, H.; Sun, Q.; Li, H. Direct conversion of waste tires into threedimensional graphene. Energy Storage Mater. 2019, 23, 499-507.

(6) Bonnia, N. N.; Zanuri, A. Z.; Asli, N. A.; Masdar, N. A.; Ratim, S.; Yahaya, S. M.; Mahat, M. M.; Ramli, R. Synthesis of Graphene Oxide from Waste Carbon Tyre using Modified Hummer's Method. Int. J. Eng. Technol. 2018, 7, 352-355.

(7) Silva, P. J.; Valezin, K.; Martins, P.; Gomes, R.; Pereira, R.; Melo, R. M.; Morandim-Giannetti, F.; Gonçalves, A.; Panzarini, R.; Marcos, L. T. Preparation of Fluorescent Carbon-BasedDots from Waste Tire Pyrolysis. J. Braz. Chem. Soc. 2020, 1-8.

(8) Novoselov, K. S.; Fal, V. I.; Colombo, L.; Gellert, P. R.; Schwab, M. G.; Kim, K. A roadmap for graphene.Nature. Nature 2012, 490, 192200.

(9) Kim, K. S.; Zhao, Y.; Jang, H.; Lee, S. Y.; Kim, J. M.; Kim, K. S.; Ahn, J. H.; Kim, P.; Choi, J. Y.; Hong, B. H. Large-scale pattern growth of graphene films for stretchable transparent electrodes. Nature 2009, 457, 706-710.

(10) Park, S.; Ruoff, R. S. Chemical methods for the production of graphenes. Nat. Nanotechnol. 2009, 4, 217-224.

(11) Bagri, A.; Mattevi, C.; Acik, M.; Chabal, Y. J.; Chhowalla, M.; Shenoy, V. B. Structural evolution during the reduction of chemically derived graphene oxide. Nat. Chem. 2010, 2, 581-587.

(12) Misbah, M.; Essawy, A.; Ramadan, R.; ElAgammy, E.; El-Kemary, M. Amino Acid-Assisted Inorganic Materials for Supercapacitors. Inorganic Nanomaterials for Supercapacitor Design; Edited By Dr. Inamuddin, R.; Boddula, M.; Ahamed, A. AsiriInamuddin, CRC Press: 2019,.

(13) Zhu, Z.; Zhang, Z.; Zhuang, Q.; Gao, F.; Liu, Q.; Zhu, X.; Fu, M. Growth of $\mathrm{MnCo} 2 \mathrm{O} 4$ hollow nano-spheres on activated carbon cloth for flexible asymmetric supercapacitors. J. Power Sources 2021, 492, 229669.

(14) Fu, M.; Lv, R.; Lei, Y.; Terrones, M. Ultralight Flexible Electrodes of Nitrogen-Doped Carbon Macrotube Sponges for High-Performance Supercapacitors. Small 2021, 17, 2004827.

(15) Fu, F.; Chen, W.; Zhu, X.; Yang, B.; Liu, Q. Crab shell derived multi-hierarchical carbon materials as a typical recycling of waste for high performance supercapacitors. Carbon 2019, 141, 748-757.

(16) Fu, M.; Chen, W.; Ding, J.; Zhu, X.; Liu, Q. Biomass waste derived multi-hierarchical porous carbon combined with $\mathrm{CoFe} 2 \mathrm{O} 4$ as advanced electrode materials for supercapacitors. J. Alloys Compd. 2019, 782, 952-960.

(17) Fu, M.; Zhu, Z.; Zhang, Z.; Zhuang, Q.; Chen, W.; Liu, Q. Microwave deposition synthesis of $\mathrm{Ni}(\mathrm{OH}) 2$ /sorghum stalk bimass carbon electrode materials for supercapacitors. J. Alloys Compd. 2020, $846,156376$.

(18) Fu, M.; Huang, J.; Feng, S.; Zhang, T.; Qian, P. C.; Wong, W. Y. One-step solid-state pyrolysis of bio-wastes to synthesize multihierarchical porous carbon for ultra-long life supercapacitors. Mater.Chem.Front. 2021, 5, 2320-2327.

(19) El-Shafai, N. M.; El-Khouly, M. E.; El-Kemary, M.; Ramadan, M. S.; Masoud, M. S. Graphene oxide-metal oxide nanocomposites: fabrication, characterization and removal of cationic rhodamine B dye. RSC Adv. 2018, 8, 13323-13332.

(20) El-Shafai, N.; El-Khouly, M. E.; Kemary, M.; Ramadan, M.; Eldesoukey, I.; Masoud, M. Graphene oxide decorated with zinc oxide 
nanoflower, silver and titanium dioxide nanoparticles: fabrication, characterization, DNA interaction, and antibacterial activity. RSC Adv. 2019, 9, 3704-3714.

(21) Zhao, X.; Zhang, L.; Murali, S.; Stoller, M. D.; Zhang, Q.; Zhu, Y.; Ruoff, R. S. Incorporation of manganese dioxide within ultraporous activated graphene for high-performance electrochemical capacitors. ACS Nano. 2012, 6, 5404-5412.

(22) Elessawy, N. A.; El Nady, J.; Wazeer, W.; Kashyout, A. B. Development of High-Performance Supercapacitor based on a Novel Controllable Green Synthesis for 3D Nitrogen Doped Graphene. Sci. Rep. 2019, 9, 1129.

(23) Mahato, N.; Parveen, M.; Cho, M. H. Graphene nanodiscs from electrochemical assisted micromechanical exfoliation of graphite: Morphology and supramolecular behavior. Mater. Express 2015, 5, 471-479.

(24) Wang, W.; Liu, Z.; Liu, Y.; Xu, C.; Zheng, C.; Wang, G. A simple wet-chemical synthesis and characterization of $\mathrm{CuO}$ nanorods. Appl. Phys. A: Mater. Sci. Process. 2003, 76, 417-420.

(25) Fang, J.; Xuan, Y. Investigation of optical absorption and photothermal conversion characteristics of binary $\mathrm{CuO} / \mathrm{ZnO}$ nanofluids. RSC Adv. 2017, 7, 56023-56033.

(26) Dervishi, E.; Ji, Z.; Htoon, H.; Sykora, M.; Doorn, S. K. Raman spectroscopy of bottom-up synthesized graphene quantum dots: size and structure dependence. Nanoscale 2019, 11, 16571-16581.

(27) Liu, W.-W.; Chai, S.-P.; Mohamed, A. R.; Hashim, U. Synthesis and Characterization of Graphene and Carbon Nanotubes: A Review on the Past and Recent Developments. J. Ind. Eng. Chem. 2014, 20, $1171-1185$

(28) Merlen, A.; Buijnsters, J.; Pardanaud, C. A Guide to and Review of the Use of Multiwavelength Raman Spectroscopy for Characterizing Defective Aromatic Carbon Solids: from Graphene to Amorphous Carbons. Coatings 2017, 7, 153.

(29) Rao, R.; Podila, R.; Tsuchikawa, R.; Katoch, J.; Tishler, D.; Rao, A. M.; Ishigami, M. Effects of Layer Stacking on the Combination Raman Modes in Graphene. ACS Nano 2011, 5, 1594-1599.

(30) Luong, D. X.; Bets, K. V.; Algozeeb, W. A.; Stanford, M. G.; Kittrell, C.; Chen, W.; Salvatierra, R. V.; Ren, M.; Hugh, E. A.; Advincula, P. A.; Wang, Z.; Bhatt, M.; Guo, H.; Mancevski, V.; Shahsavari, R.; Yakobson, B. I.; Tour, J. M. Gram-scale bottom-up flash graphene synthesis. Nature 2020, 577, 647-651.

(31) Wu, J.-B.; Lin, M.-L.; Cong, X.; Liua, H.-N.; Tan, P.-H. Raman spectroscopy of graphene-based materials and its applications in related devices. Chem. Soc. Rev. 2018, 47, 1822-1873.

(32) Fasbender, S.; Zimmermann, L.; Cadeddu, R. P.; Luysberg, M.; Moll, B.; Janiak, C.; Heinzel, T.; Haas, R. The Low Toxicity of Graphene Quantum Dots is Reflected by Marginal Gene Expression Changes of Primary Human Hematopoietic Stem Cells. Sci. Rep. 2019, 9, 12028.

(33) Zhang, Y.; Liu, Q.; Zhang, S.; Zhang, Y.; Zhang, Y.; Liang, P. Characterization of kaolinite/styrene butadiene rubber composite: Mechanical properties and thermal stability. Appl. Clay Sci. 2016, 124125, 167-174.

(34) Farida, E.; Bukit, N.; Ginting, E. M.; Bukit, B. F. The effect of carbon black composition in natural rubber compound. Case Stud. Therm. Eng. 2019, 16, 100566.

(35) Liu, R.; Wu, D.; Feng, X.; Müllen, K. Bottom-up fabrication of photoluminescent graphene quantum dots with uniform morphology. $J$. Am. Chem. Soc. 2011, 133, 15221-15223.

(36) Faiz, M. S.; Azurahanim, C. A.; Yazid, Y.; Suriani, A. B.; Ain, M. N. Preparation and characterization of graphene oxide from tea waste and it's photocatalytic application of $\mathrm{TiO}_{2} /$ graphene nanocomposite. Mater. Res. Express 2020, 7, No. 015613.

(37) Kavitha, C.; Bramhaiahb, K.; John, N. S. Low-cost electrochemical detection of l-tyrosine using an $\mathrm{rGO}-\mathrm{Cu}$ modified pencil graphite electrode and its surface orientation on a $\mathrm{Ag}$ electrode using an ex situ spectroelectrochemical method. RSC Adv. 2020, 10, 2287122880.

(38) Muñoz-Sandoval, E.; Fajardo-Díaz, J. L.; Sánchez-Salas, R.; Cortés-López, A. J.; López-Urías, F. Two Sprayer CVD Synthesis of
Nitrogen-doped Carbon Sponge-type Nanomaterials. Sci. Rep. 2018, 8, 2983.

(39) Li, Y.; Zhao, Y.; Cheng, H.; Hu, Y.; Shi, G.; Dai, L.; Qu, L. Nitrogen-Doped Graphene Quantum Dots with Oxygen-Rich Functional Groups. J. Am. Chem. Soc. 2012, 134, 15-18.

(40) Patil, U. V.; Pawbake, A. S.; Machuno, L. G. B.; Gelamo, R. V.; Jadkar, S. R.; Rout, C. S.; Late, D. J. Effect of plasma treatment on multilayer graphene:X-ray photoelectron spectroscopy, surface morphology investigations and work function measurements. RSC Adv. 2016, 6, 48843-48850.

(41) Fathy, M.; Gomaa, A.; Taher, F. A.; El-Fass, M. N.; Kashyout, A. E.-H. B. Optimizing the preparation parameters of GO and rGO for large-scale production. J. Mater. Sci. 2016, 51, 5664-5675.

(42) Gong, P.; Hou, K.; Ye, X.; Ma, L.; Wang, J. Synthesis of highly luminescent fluorinated graphene quantum dots with tunable fluorine coverage and size. MaterialsLetters 2015, 143, 112-115.

(43) Zheng, Y.; Ge, Y.; Jaroniec, M.; Qiao, S. Z. Two Step Boron and Nitrogen Doping in Graphene for Enhanced Synergistic Catalysis. Am. Ethnol. 2013, 52, 3192-3198.

(44) Yeh, T.; Teng, C.; Chen, S.; Teng, H. Nitrogen-Doped Graphene Oxide Quantum Dots as Photocatalysts for Overall Water-Splitting under Visible Light Illumination. Adv. Mater. 2014, 26, 3297-3303.

(45) Permatasari, F. A.; Aimon, A. H.; Iskandar, F.; Ogi, T.; Okuyama, $\mathrm{K}$. Role of $\mathrm{C}-\mathrm{N}$ Configurations in the Photoluminescence of Graphene Quantum Dots Synthesized by a Hydrothermal Route. Sci. Rep. 2016, 6, 21042.

(46) Post, P.; Wurlitzer, L.; Maus-Friedrichs, W.; Weber, A. B. Characterization and Applications of Nanoparticles Modified in-Flight with Silica or Silica-Organic Coatings. Nanomater. 2018, 8, 530.

(47) Fu, Y.; Gao, G.; Zhi, J. Electrochemical synthesis of multicolor fluorescent $\mathrm{N}$-doped graphene quantum dots as a ferric ion sensor and their application in bioimaging. J. Mater. Chem. B 2019, 7, 1494-1502.

(48) Mintcheva, N.; Gicheva, G.; Panayotova, M.; Kulinich, S. A. Room-Temperature Synthesis of $\mathrm{ZnS}$ Nanoparticles Using Zinc Xanthates as Molecular Precursors. Materials. 2020, 13, 171.

(49) Santos, W.; Costa, C.; Cardoso, D.; Rodrigues, E.; Dias, L.; Oliveira, R.; Oliveira, R.; Junior, S.; Machado, N. Fuel production from waste tire using aluminum and kaolin industry waste as a catalyst. Braz. J. Chem. Eng. 2020, 92, 1129-1135.

(50) Zhou, Y.; Bao, Q.; Tang, L. A. L.; Zhong, Y.; Loh, K. P. Hydrothermal Dehydration for the "Green" Reduction of Exfoliated Graphene Oxide to Graphene and Demonstration of Tunable Optical Limiting Properties. Chem. Mater. 2009, 21, 2950-2956.

(51) Ţucureanu, V.; Matei, A.; Avram, A. M. FTIR Spectroscopy for Carbon Family Study. Crit. Rev. Anal. Chem. 2016, 46, 502-520.

(52) Wang, T.; Wang, L.; Wu, D.; Xia, W.; Zhao, H.; Jia, D. Hydrothermal synthesis of nitrogen-doped graphene hydrogels using amino acids with different acidities as doping agents. J.Mater.Chem. A. 2014, 2, 8352-8361.

(53) Jamila, G. S.; Sajjad, S.; Leghari, S. A. K.; Mahmood, T. Role of nitrogen doped carbon quantum dots on $\mathrm{CuO}$ nano-leaves as solar induced photo catalyst. J. Phys. Chem. Solids 2020, 138, 109233.

(54) Wiliams, A. T. R.; Winfield, S. A.; Miller, J. N. Relative fluorescence quantum yields using a computer-controlled luminescence spectrometer. Analyts 1983, 108, 1067-1071.

(55) Deng, J.; Lu, Q.; Mi, N.; Li, H.; Liu, M.; Xu, M.; Tan, L.; Xie, Q.; Zhang, Y.; Yao, S. Electrochemical synthesis of carbon nanodots directly from alcohols. Chemistry - A European Journal 2014, 20, 49934999.

(56) Zygouri, P.; Tsoufis, T.; Kouloumpis, A.; Patila, M.; Potsi, G.; Sevastos, A. A.; Sideratou, Z.; Katsaros, F.; Charalambopoulou, G.; Stamatis, H.; Rudolf, P.; Steriotis, T. A.; Gournis, D. Synthesis, characterization and assessment of hydrophilic oxidized carbon nanodiscs in bio-related applications. RSC Adv. 2018, 8, 122-131.

(57) Yan, R.; Wu, H.; Zheng, Q.; Wang, J.; Huang, J.; Ding, K.; Guoa, Q.; Wang, J. Graphene quantum dots cut from graphene flakes: High electrocatalytic activity for oxygen reduction and low cytotoxicity. RSC Adv. 2014, 4, 23097-23106. 
(58) Azman, N. H.; Mamat, M. S.; Nazir, M.; Ngee, L. H.; Sulaiman, Y. Graphene-based ternary composites for supercapacitors. Int. J. Energy Res. 2018, 42, 2104-2116.

(59) Hao, J.; Liao, Y.; Zhong, Y.; Shu, D.; He, S.; Guo, S.; Huang, Y.; Zhong, J.; Hu, L. Three-Dimensional Graphene Layers Prepared by a Gas-Foaming Method for Supercapacitor Applications. Carbon 2015, 94, 879-887.

(60) Allison, A.; Andreas, H. A. Minimizing the Nyquist-plot semicircle of pseudocapacitive manganese oxides through modification of the oxide-substrate interface resistance. J. Power Sources 2019, 426, 9396.

(61) ShoarAbouzari, M. R.; Berkemeier, F.; Schmitz, G.; Wilmer, D. On the physical interpretation of constant phase elements. Solid State Ionics 2009, 180, 922-927.

(62) Gong, Y.; Li, D.; Fu, Q.; Pan, C. Influence of graphene microstructures on electrochemical performance for supercapacitors. Prog. Nat. Sci.: Mater. Int. 2015, 25, 379-385.

(63) Alyobi, M. M.; Barnett, C. J.; Rees, P.; Cobley, R. J. Modifying the electrical properties of graphene by reversible point-ripple formation. Carbon 2018, 143, 762-768.

(64) Arunkumar, M.; Paul, A. Importance of Electrode Preparation Methodologies in SupercapacitorApplications. ACS Omega 2017, 2, 8039-8050.

(65) Tang, N.; Tang, T.; Pan, H.; Sun, Y.; Chen, C.; Du, Y. Magnetic Properties of Gaphene, Chapter 6, in Spintronic 2D Materials; Elsevier: Page: 137-161, Edited by Wenqing Liu and Yongbing Xu, 2020,Mateials Today.

(66) Zhao, D.; Jiang, K.; Li, J.; Zhu, X.; Ke, C.; Han, S.; Kymakis, E.; Zhuang, X. Supercapacitors with alternating current line-filtering performance. BMC Mater. 2020, 2, 3.

(67) Fan, Z.; Islam, N.; Bayne, S. B. Towards kilohertz electrochemical capacitors for filtering and pulse energy harvesting. Nano Energy 2017, 39, 306-320.

(68) Zhang, S.; Sui, L.; Dong, H.; He, W.; Dong, L.; Yu, L. HighPerformance Supercapacitor of Graphene Quantum Dots with Uniform Sizes. ACS Appl. Mater. Interfaces 2018, 10, 12983-12991. 